\section{The Search for the Authentic Citron (Citrus medica L.): Historic and Genetic Analysis}

\author{
Elisabetta Nicolosi and Stefano La Malfa \\ Dipartimento di OrtoFloroArboricoltura e Tecnologie Agroalimentari, \\ University of Catania, Italy
}

\section{Mohamed El-Otmani}

Department of Horticulture, Institut Agronomique et Veterinaire Hassan II, Complexe Horticole d'Agadir, BP 728, Agadir 80000, Morocco

\section{Moshe Negbi and Eliezer E. Goldschmidt ${ }^{1}$}

The Kennedy-Leigh Center for Horticultural Research, The Robert H. Smith Institute of Plant Sciences and Genetics in Agriculture, The Hebrew University of Jerusalem, Rehovot, Israel 76100

The history of citrus and its spread from the centers of origin in Southeast Asia to the Mediterranean and other continents is a fascinating story that has been reported in

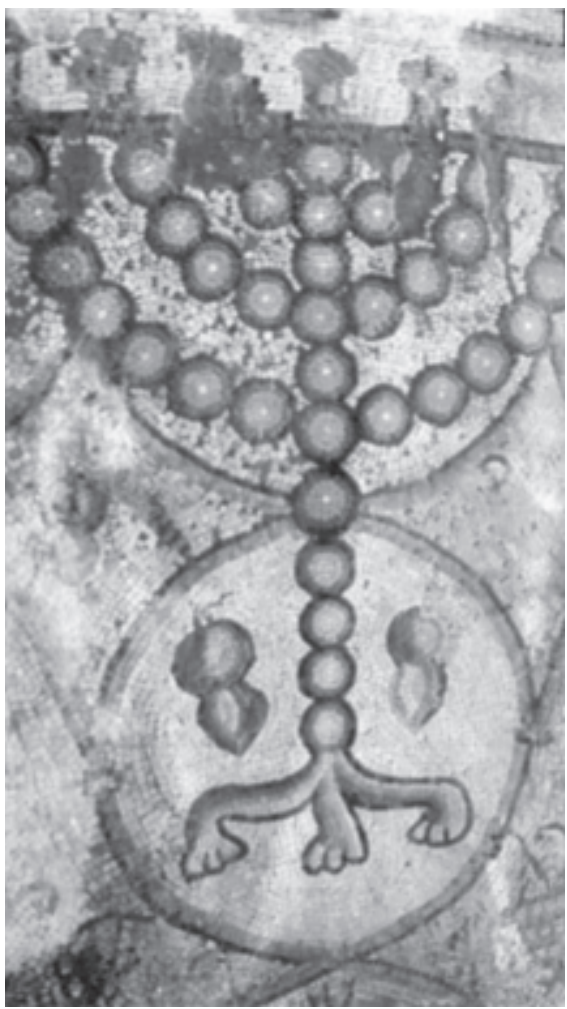

Fig. 1. A mosaic from the floor of a sixth century C.E. synagogue at Maon, in the Northern Negev, Israel, showing two citron fruits, on both sides of the base of the sanctual candelabrum. The citrons reveal the belt phenomenon (Goldschmidt, 1976) which according to Bar-Joseph (2003) is a symptom of viroid infection.

Received for publication 23 June 2005. Accepted for publication 28 July 2005. We thank Aliza Vardi and M Bar-Joseph for critical reading and valuable comments on the manuscript. Financial support to E.E.G by the Y.M and R.Kibilevitch Fund for Citron Research is gratefully acknowledged.Special thanks to E. Tribulato for his ongoing support and encouragement of this research project.

To whom all correspondence should be addressed; e-mail goldsmit@agri.huji.ac.il. considerable detail (Calabrese, 1998; Chapot, 1975; Tolkowsky, 1938). It is well accepted that the citron was the first citrus fruit to reach the Near East and the Mediterranean. In addition to its medical qualities which had already been recognized by Theophrastus and the Roman Naturalists, the citron has been, and is still being used by the Jews for worship during the feast of Tabernacles. Thus the citron became a Jewish symbol and there is ample archaeological (Fig. 1) as well as textual evidence demonstrating its presence in Palestine from the second century B.C. onwards. According to most authorities, the next-to-arrive citrus fruits, lemon and sour orange, reached the Mediterranean only much later, during the Arabic era (7th century and onwards). This means that for a long time, perhaps as much as 1000 years, citrons were the only citrus fruit known in this area. Citrons were still very important during the 17 th and 18 th centuries, as indicated by the long text and numerous illustrations devoted to them in Hesperides of Ferrari (1646) (Fig. 2) and Volkamer (1708) (Fig. 3).

The art of grafting was known to the Greeks and the Romans as well as to their Jewish contemporaries. According to the Jewish law grafting was permitted between two cultivars of the same species but interspecific grafts were prohibited. In the Talmudic sources of the Jewish law we find a list of permissible and

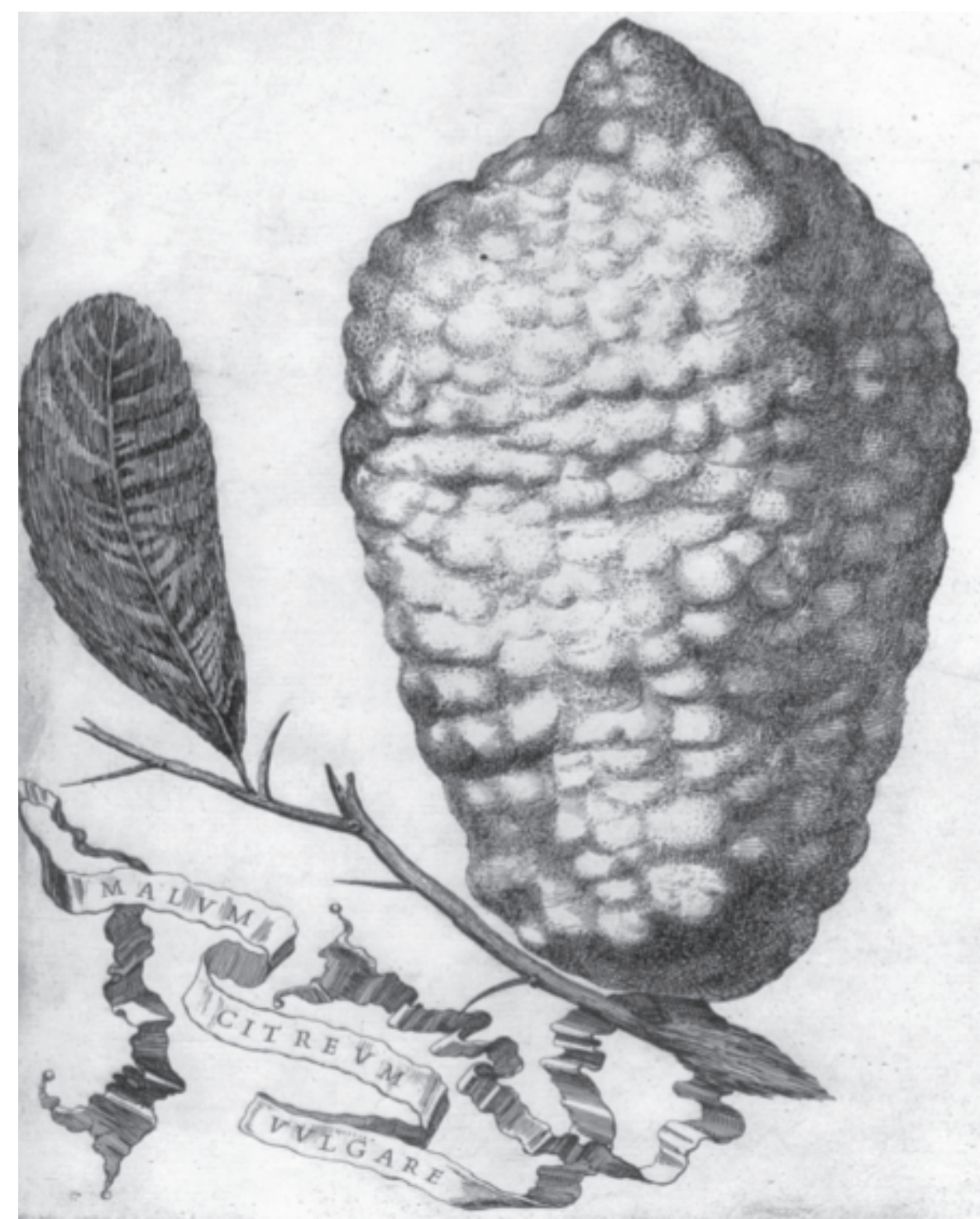

Fig. 2. Picture of a citron fruit from the Hesperides of Ferrari (1646). 

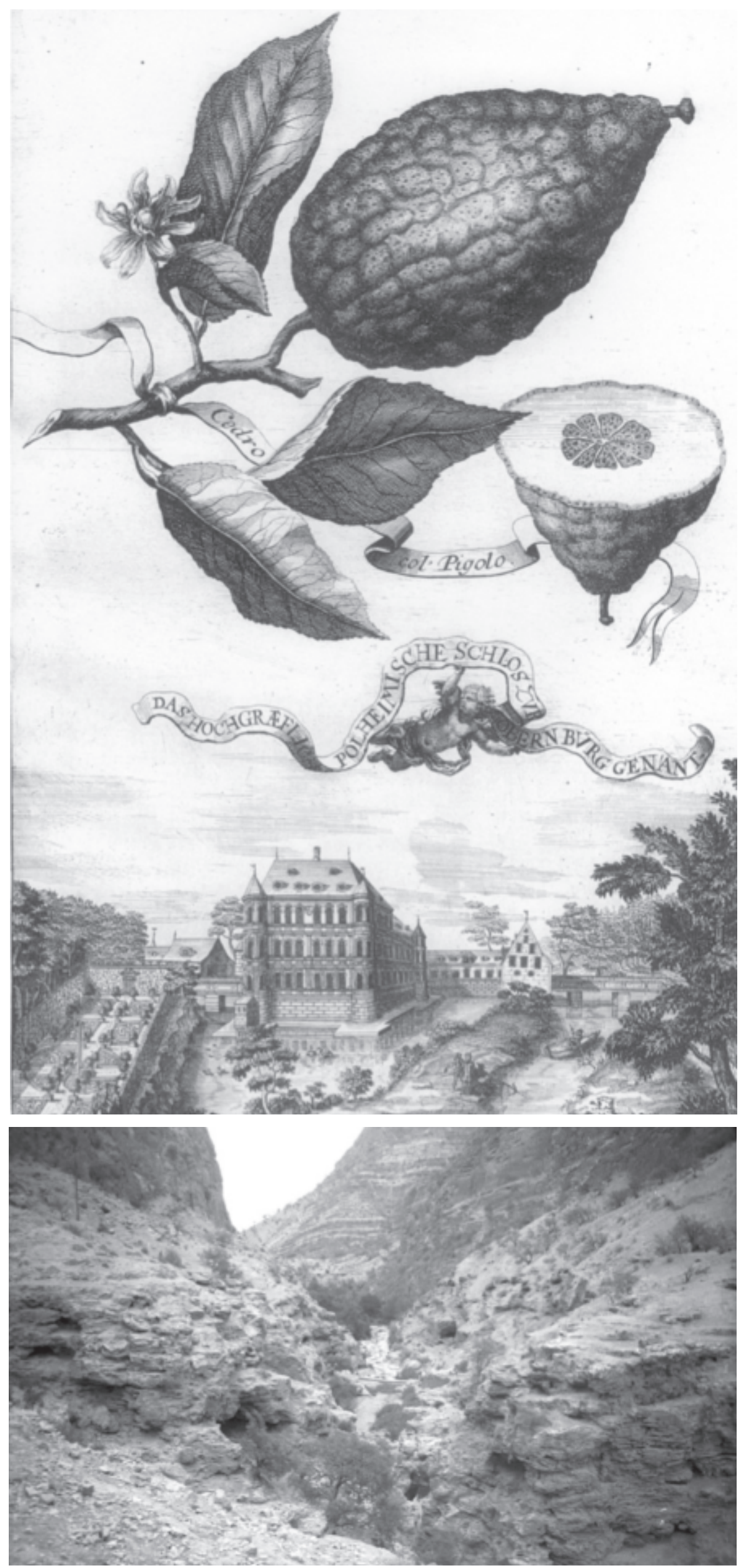

Fig. 3. Picture of a citron fruit with a persistent style (Cedro col Pigolo) from the Nürnbergische Hesperides of Volkamer (1708).

forbidden grafts among fruit trees; the citron is not mentioned in this list [Kilayim I:4], nor is grafting of the citron mentioned in the discussion of citron properties [Sukkah III 5-7]. In fact, very little is known about the history of citrus grafting, such as when and how it began. If our assumption that other citrus fruits did not reach the region before the Arabic era is correct, it might be concluded that grafting of citron on other citrus species could not have been practiced around the Mediterranean before the Arabic era, when potential citrus rootstocks became available.

May a citrus fruit from a grafted tree be used for the ritual of the feast of Tabernacles? The earliest comments on use of fruit from grafted trees occur in two Rabbinic Responsa, from Italy and Palestine, during the second half of the 16th century (Goldschmidt, 1981). From the way the problem was raised it may be inferred that grafting of citrons was already widely practiced during that time. Both respondents opposed the use of the grafted citron, and of the same opinion were also the majority of those who discussed the issue during the 17 th and 18 th centuries. Furthermore, some Rabbis expressed the view that even citron fruits which develop on a tree raised from cuttings excised from a grafted tree (or from seed of fruit from a grafted tree), should not be used on Tabernacles. The acceptance of this extreme view created a new situation. As long as the question was whether a certain tree was grafted or not, careful inspection of the tree could settle the problem. Now, however, the question became whether the propagation material from which the current tree (or one of its ancestors) was started was derived from a grafted tree. To the best of our knowledge, even today, with all the modern, molecular techniques, there is no way of answering this question and establishing the never-grafted nature of a citron tree. This has, in fact, cast doubt on all the citrons growing in the traditional areas of cultivation around the Mediterranean, since it was impossible to state with certainty that any of them were nongrafted.

Although the verdict that declared the grafted citron unfit was reached almost unanimously, the rational provided varied considerably (Goldschmidt, 1981). This indicates, in our opinion, that there was insufficient understanding of the nature of grafting among plants. The argument most frequently raised was that the grafted plant is a mix of the stock and the scion (just as the mule is a hybrid of its parents, the horse and the donkey). Therefore, the grafted citron is not a true (or whole) citron, since the rootstock, which belongs to a different species, contributes to the fruit's consistency. This view, which nowadays seems strange or even ridiculous, did not appear as such several hundred years ago. Since Roman times, throughout the Middle Ages, and up to the 20th century (Greene, 1983; Pease, 1933),

Fig. 4. The ascent into the Assads mountain area where the Morocco citrons are grown.

HortScience Vol. 40(7) December 2005 

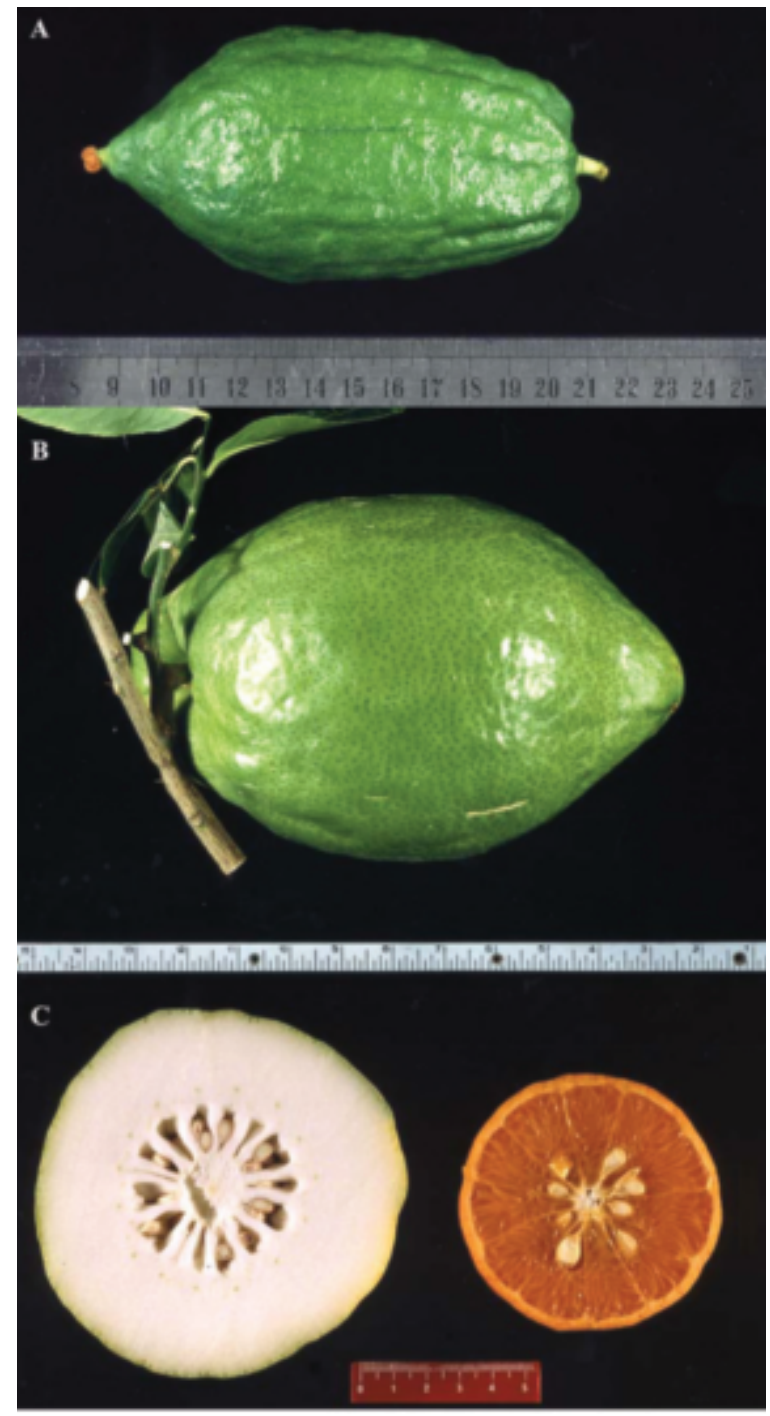

Fig. 5. (A) A Morocco citron with a persistent style. (B) A large (about10 lbs.) Yemen citron; note the absence of a persistent style. (C) Cross sections of a thick-peeled Yemen citron (left) and, for comparison, a thinpeeled 'Murcott' tangor (right). Note the complete absence of juice vesicles in the Yemen citrons, only seed are present in the empty locules.

the scholar Gallesio (1811), who was certainly aware of the suspicious attitude towards grafting, writes that he examined a large number of citrus stock-scion combinations and never observed anything unusual in the outcome of such grafts.

While grafting is not expected, according to current scientific views, to introduce genetic changes, other potential sources of genetic variability must be considered [see recent reports that grafting may involve gene silencing and other genetic effects (Kim et al., 2001; Palauqui et al., 1997; Sonoda and Nishiguchi, 2000)]. Formation of citron hybrids due to pollination by other citrus species appears to be a real threat if propagation by seed is practiced. However, such hybrids would probably be easily identified and discarded by the citron growers unless their fruit characteristics remain close enough to the citron parent. Viral and viroid diseases may also be inheritable if vegetative propagation methods are used and have apparently been associated with citrons since antiquity (Bar Joseph, 2003). Lemon is genetically very close to the citron (Nicolosi et al., 2000) and natural crosses between lemon and citron might be difficult to discern. At least one such hybrid has been recently identified: the 'Interdonato' lemon has been shown to be a citron $\times$ lemon hybrid (Deng et al., 1995).

\section{The Search for Nongrafted Citrons}

The problem of the grafted citron became a major source of concern for the Jewish community from the late 16 th century onwards. The problem seemed particularly intriguing to Jews of northern Europe, who could not observe the citron trees growing and had to rely on information from tradesman who imported the fruit from the Mediterranean.

The first Responsa dealing with the topic came from Italy (about 1575) and the author recommends the use of the citrons growing in southern Italy, in Calabria, which were regarded as nongrafted (The 'Riviera dei cedri' in Calabria is an important citron growing center even today). However, suspicions have subsequently been raised even with regard to those growing areas, along with the conviction that inspection of the trees alone cannot tell us anything about the source of the propagation material from which the trees had been started. This has prompted a search for the authentic citron, a citron tree, which neither it nor any of its ancestors or preancestors have been grafted.

The search was extended from the classical Mediterranean growing areas to distant regions where citrons were assumed to be endemic and may have never been grafted. Among those, careful consideration must be given to the citron types growing in the remote areas of Morocco there was a notion that interspecific grafting may lead to the appearance of an entirely different plant species. One of the often mentioned examples is that of the white mulberry which has allegedly been derived by grafting the black mulberry on the white poplar (Greene, 1983). These scientific views were possibly known to the Rabbis who discussed the problem and may have influenced their rejection of the use of the grafted citron. Interestingly,

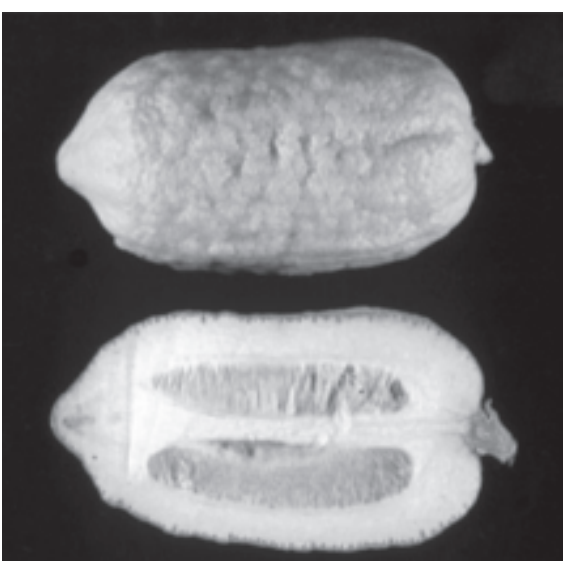

Fig. 6. A longitudal section of a seedless Morocco citron.

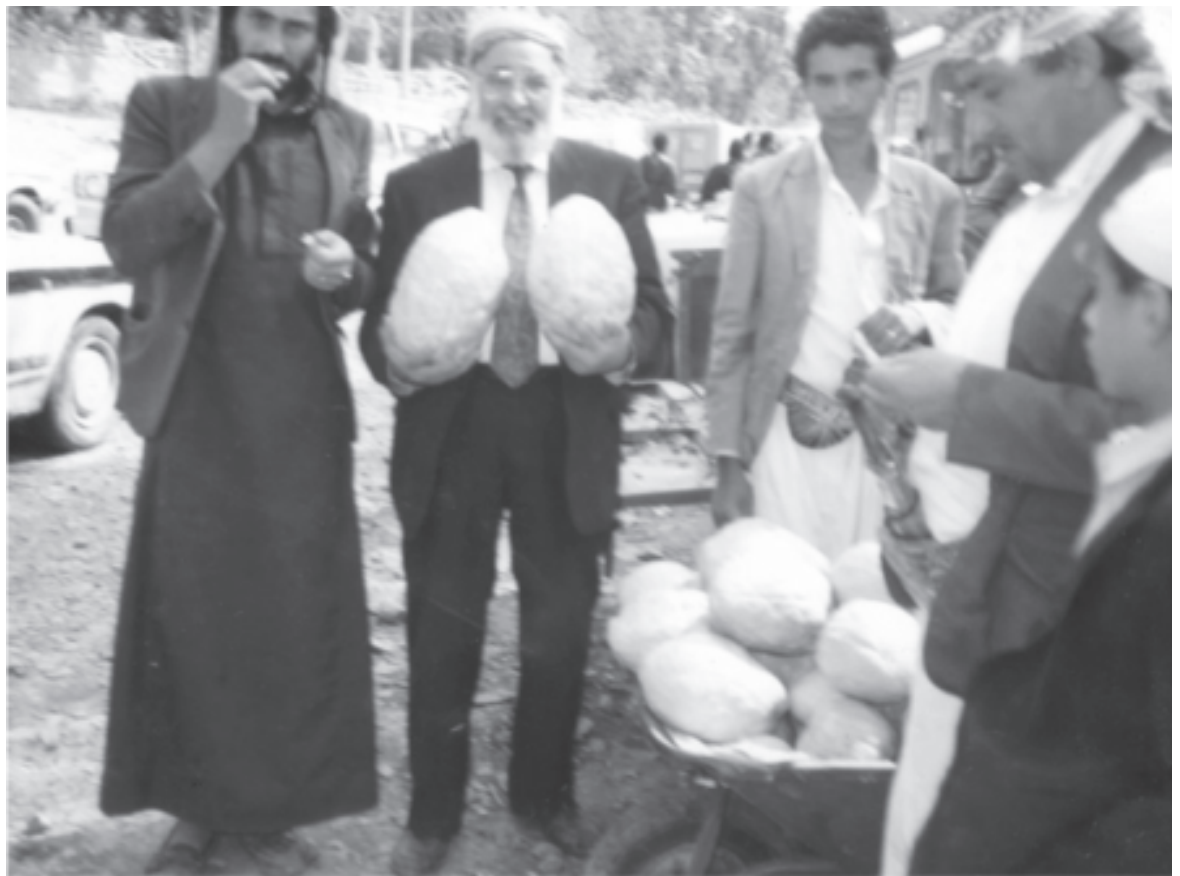

Fig. 7. Citron trade in a local market in a village, north of San'a, Yemen. Photograph provided by Rabbi Zemach Q'adi Halevy, an American citizen, who visited Yemen in 1995. He appears in the picture, holding two large citron fruit. 


\begin{tabular}{ll}
\hline Code & Type and origin \\
\hline TG-P & Yemen \\
TA-P & Yemen \\
T-Z & Yemen \\
M-P & Morocco \\
M-G & Morocco \\
K-K & Kibilevitch, Israel \\
B-Z & Braverman, Israel \\
HH-Z & Hazon-Ish Halperin, Israel \\
HL-Z & Hazon-Ish Lefkovich, Israel \\
C-C & Calabria Chabad, Israel \\
D-I & Diamante, Italy \\
E-I & Etrog, Italy \\
\hline
\end{tabular}

\begin{tabular}{lclc}
\hline SCAR primer & Bases (no.) & Sequence & Annealing temp $\left({ }^{\circ} \mathrm{C}\right)$ \\
\hline SC3 & 24 & TCCgATgCTgTTgAgTTggCTAAT & 65 \\
& 24 & TCCgATgCTgCAgTTgTAgCTTCC & 62 \\
SC7 & 20 & AgACCCAgAgTgAAgATgAg & 6 \\
& 20 & AgACCCAgAgAgCACACAAA & \\
\hline
\end{tabular}

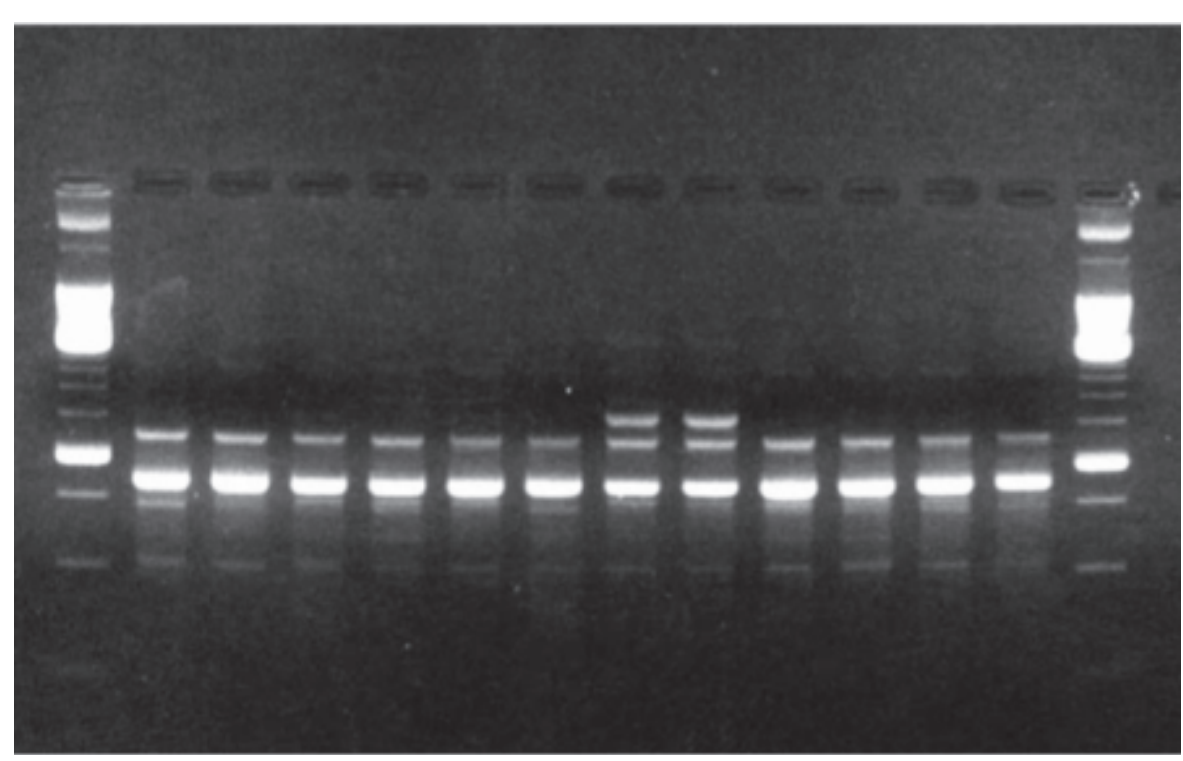

Table 3. Sequence of cpDNA universal primer.

\begin{tabular}{|c|c|c|c|}
\hline Forward & & Reverse & \\
\hline trnD & 5'-ACCAATTgAACTACAATCCC-3' & $\operatorname{trn} \mathrm{T}$ & 5'-CTACCACTgAgTTAAAAggg-3' \\
\hline $\operatorname{trn} \mathrm{H}$ & 5'-ACgggAATTgAACCCgCgCA-3' & $\operatorname{trn} \mathrm{K}$ & 5'-CCgACTAgTTCCgggTTCgA-3' \\
\hline $\operatorname{trn} \mathrm{M}$ & 5'-TgCTTTCATACggCgggACT-3' & $r b c \mathrm{~L}$ & 5'-gCTTTAgTCTCTgTTTgTgg-3' \\
\hline
\end{tabular}

ticulata Blanco, Citrus limon (L.) Burm. F. and Citrus aurantium L. were sampled for molecular analysis. Total DNA was extracted from young leaves according to the protocol of Doyle and Doyle (1987) as modified by Deng et al. (1995).

RAPD analysis. In total, 60 decamer primers (Operon Technologies) were used for RAPD analysis. Among these were included in this analysis the primers that generated specific bands for pummelo, mandarin, lemon and sour orange as reported in Nicolosi et al. (2000).

Amplification was performed in a Cetus GenAmp PCR System 9600 (Perkin Elmer) using the reaction mixtures and PCR parameters described by Deng et al. (1995). Amplification products were separated on a $1.5 \%$ agarose gel in $0.5 \times$ TBE buffer, stained with ethidium bromide and detected under UV light.

SCAR analysis. Two pairs of SCAR primers (Table 2) specific for citron, previously identified (Nicolosi et al., 2000) were used to

Fig. 8. Randomly amplified polymorphic DNA (RAPD) profile generated by primer G10 showing a polymorphic band of HH-Z and HL-Z (lanes 7 and 8).

and Yemen which have been surmised to be authentic, nongrafted citrons.

In the Souss region of Southern Morocco, in the isolated canyon of Assads in the distant Anti-Atlas mountain range, citrons have been grown for many generations as the only citrus cultivar (Fig. 4). The Assads citron cultivar has been described by Chapot (1950). It has a few specific identifying characteristics: its flowers are cream-white, lacking the typical pink pigmentation. Many, but not all of the fruit have a persistent style (Fig. 5A). The fruit are partly seedless, resulting in an elongated, slender shape (Fig. 6). As verified by some of the authors (EEG and MEO) during a recent excursion to Assads, grafting is not practiced in the Assads region even today.

The Yemen citron [not described by Hodgson (1967)] reaches a very large size - the specimen in Fig. $5 \mathrm{~B}$ is $>10$ pounds. It does not have a persistent style. Its most distinct feature is the absolute lack of juice vesicles; most of the fruit volume is taken by the albedo and the locules contain only seed (Fig. 5C). The Yemen citron was introduced to Israel by Yemenite immigrants abut 120 years ago and according to their tradition was never grafted. Citrons are grown and traded in Yemen even today (Fig. 7).

In view of the marked diversity in geographical origin and fruit characteristics, one may wonder whether the different citron types are genetically close to one another. Moreover, the Yemenite type resembles in its external appearance some Indian citrus fruits. Could the Yemenite citron have arrived from India via the sea and actually belong to a different citrus species? These doubts prompted us to undertake a genetic comparison between 12 different citron types, including types from Israel, Italy, Morocco and Yemen.

According to the currently acceptable phylogenetic theory of Barrett and Rhodes (1976), citron, pummelo and mandarin are believed to be three true species of the genus Citrus, from which all other types of citrus originated. This concept has gained further support from biochemical and molecular studies (Moore, 2001; Nicolosi et al., 2000). In the present study we approached the diversity among citron types using RAPD, SCAR, and cpDNA analysis previously employed in a wide study on citrus genetic origin and phylogeny (Nicolosi et al., 2000).

A preliminary account of this research was presented as a poster in the IX Intl. Congress of Citriculture (Nicolosi et al., 2000).

\section{Materials and Methods}

Plant materials and DNA extraction. Twelve genotypes belonging to the species Citrus medica L. (Table 1) and one genotype each of Citrus maxima Merr., Citrus reamplify DNA of all the genotypes tested. PCR was performed for 30 cycles with the annealing temperature reported in table 2 .

Chloroplast DNA analysis. The cpDNA of the 12 citron genotypes and of one accession each for pummelo, mandarin, lemon and sour orange, was amplified using 3 pairs of universal primers (Table 3 ) (Demesure et al., 1995). The obtained cpDNA fragments were digested with 12 restriction endonucleases $(A l u$ I, Taq I, Hinf I, Tru9 I, Sau3 A I, Hae III, Rsa I, Mva I, Xba I, Hha I, Sty I, Sma I) and then electrophoresed on $2 \%$ agarose gels.

The PCR consisted of $5 \mathrm{ng}$ of template DNA, $1 \times$ buffer [1.0 mL TRIS- $\mathrm{HCl}, 500 \mathrm{~mm}$ $\mathrm{KCl}(\mathrm{pH} 8.3)], 1.5 \mathrm{mM} \mathrm{MgCl}, 0.2 \mathrm{mM}$ dNTP, 2 $\mu \mathrm{L} \mathrm{Taq}$ polymerase, $1 \mu \mathrm{M}$ of each primer. The parameters of the amplification reaction were: 1 cycle of 2 min at $92^{\circ} \mathrm{C} ; 10$ cycles of $5 \mathrm{~s}$ at $92{ }^{\circ} \mathrm{C}, 15 \mathrm{~s}$ at $55^{\circ} \mathrm{C}, 1 \mathrm{~min}$ at $72{ }^{\circ} \mathrm{C}$, and 20 cycles of $5 \mathrm{~s}$ at $92{ }^{\circ} \mathrm{C}, 15 \mathrm{~s}$ at $55^{\circ} \mathrm{C}, 1 \mathrm{~min}$ at $72^{\circ} \mathrm{C}$ (extension); the length of extension was increased by $10 \mathrm{~s}$ for each cycle. Finally, an end cycle of $10 \mathrm{~min}$ at $72^{\circ} \mathrm{C}$ was performed.

Data analysis. The stable amplification products showing polymorphisms were scored as 1 for presence and 0 for absence. The polymorphisms were analyzed by pairwise comparisons of the genotypes based on the percentage of common fragments, and a similarity matrix (F value) was estimated (Nei and $\mathrm{Li}, 1979$ ). Unweighted pair group method with arithmetic mean (UPGMA) and neighbor joining (NJ) methods from phylogenetic analysis using parsimony (PAUP) were used 


\begin{tabular}{|l|l|l|l|l|l|l|l|l|l|l|l|l|}
\hline & TG-P & TA-P & M-P & K-K & B-Z & T-Z & HH-Z & HL-Z & M-G & C-C & E-I & D-I \\
\hline TG-P & 1.000 & & & & & & & & & & & \\
\hline TA-P & 0.991 & 1.000 & & & & & & & & & & \\
\hline M-P & 0.986 & 0.982 & 1.000 & & & & & & & & & \\
\hline K-K & 0.965 & 0.962 & 0.957 & 1.000 & & & & & & & & \\
\hline B-Z & 0.976 & 0.985 & 0.968 & 0.959 & 1.000 & & & & & & & \\
\hline T-Z & 0.991 & 0.988 & 0.983 & 0.962 & 0.979 & 1.000 & & & & & & \\
\hline HH-Z & 0.971 & 0.968 & 0.957 & 0.960 & 0.971 & 0.968 & 1.000 & & & & & \\
\hline HL-Z & 0.963 & 0.954 & 0.955 & 0.963 & 0.963 & 0.960 & 0.980 & 1.000 & & & & \\
\hline M-G & 0.983 & 0.985 & 0.986 & 0.960 & 0.971 & 0.974 & 0.960 & 0.952 & 1.000 & & & \\
\hline C-C & 0.977 & 0.968 & 0.974 & 0.949 & 0.965 & 0.968 & 0.960 & 0.958 & 0.971 & 1.000 & & \\
\hline E-I & 0.974 & 0.965 & 0.965 & 0.963 & 0.974 & 0.977 & 0.962 & 0.960 & 0.962 & 0.968 & 1.000 & \\
\hline D-I & 0.977 & 0.968 & 0.974 & 0.948 & 0.965 & 0.968 & 0.954 & 0.957 & 0.971 & 0.994 & 0.968 & 1.000 \\
\hline
\end{tabular}

primers, as expected, generated each only a monomorphic band (SC3-600bp and SC7-1000bp) confirming the presence of the specific dominant-homozygotic band in all the citrons tested.

The cpDNA analysis did not reveal any polymorphism among the 12 tested citron accessions while polymorphisms were detected between the citron group and the other four species analyzed.

All the genotypes showed high $\mathrm{F}$ values (Fig. 9). The highest similarity (0.994) was found between Calabria Chabad and Diamante Italy, while the lowest similarity (0.948) between Diamante Italy and Kibilevitch Israel. All these results suggest a common origin and a high level of

Fig. 9. Similarity matrix with F value (Nei and Li, 1979) among the 12 citron accessions.

for phylogenetic analysis and tree construction (Swofford, 1993).

\section{Results}

The 60 tested 10 -mer primers generated 190 fragments, among them, 160 were monomorphic while 30 showed polymorphisms (Fig.8). The RAPD profiles of each primer consists of 2 to 9 bands, ranging in size form 300 to $1750 \mathrm{bp}$. None of the specific markers previously characterized (Nicolosi et al., 2000) for pummelo, mandarin, lemon and sour orange was recorded in the analysed citrons (data not shown). Moreover the 30 polymorphic bands allowed us to discriminate all the 12 citron accessions.

The amplification with the two SCAR

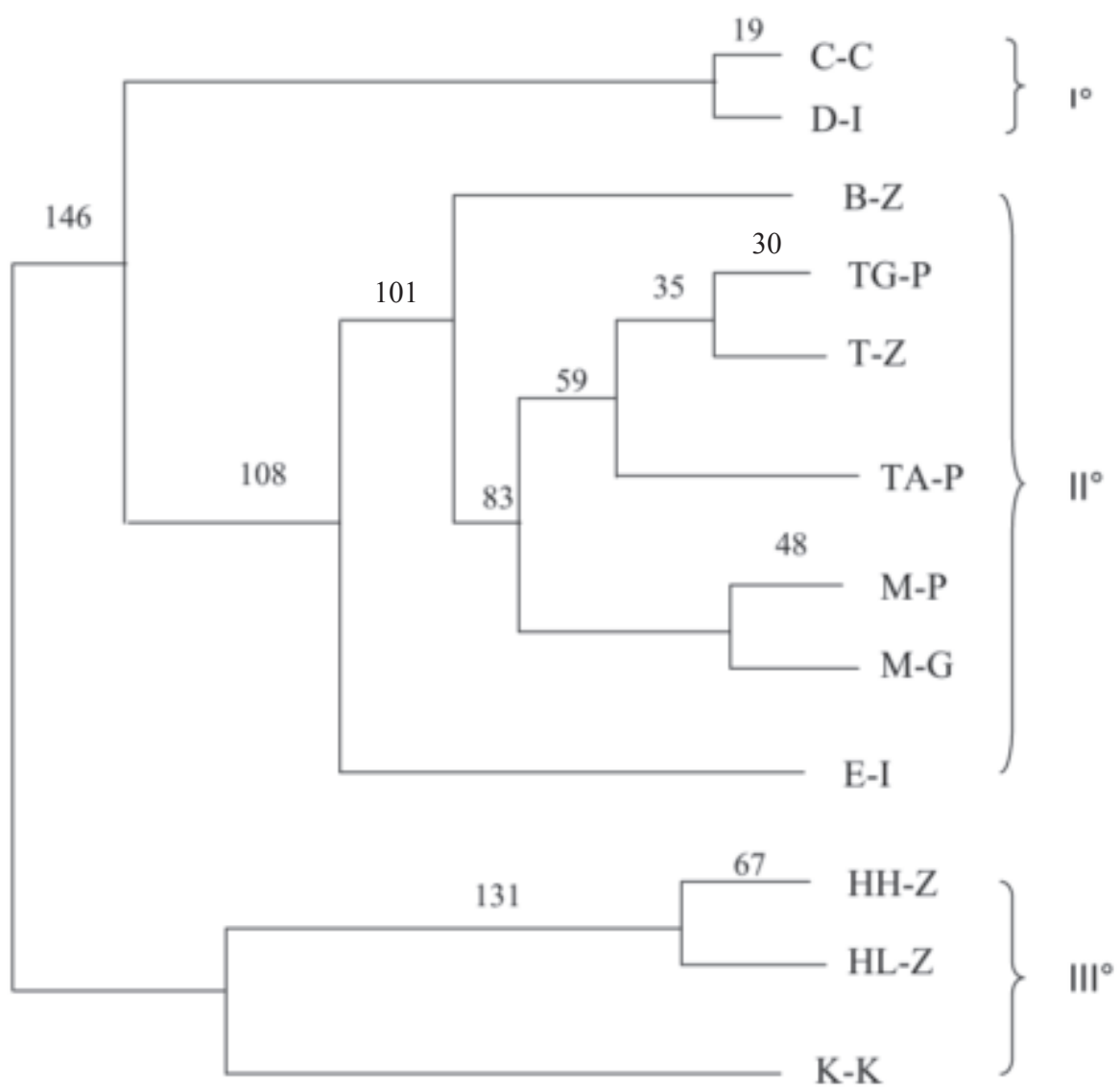

Fig. 10. Unweighted pair group method with arithmetic mean (UPGMA) dendrogram revealing three different clusters with confidence levels for arms. genetic uniformity of the tested citrons.

Phylogenetic analysis performed with NJ and UPGMA gave consistent results, and the dendrograms obtained were rather similar. The consensus UPGMA dendrogram (Fig. 10) showed three different clusters: the first one comprises Calabria Chabad and Diamante Italy; in the second one are included all the citrons from Yemen and Morocco, except for B-Z from Israel and E-I from Italy. The third cluster comprises three Israeli genotypes.

\section{Discussion}

The results of the genetic analysis are unequivocal and do not leave much room for interpretation. In spite of diverse geographical origin and the considerable morphological variation in fruit size and shape, presence of pulp and persistence of style, all the citron types examined revealed a high degree of similarity. Focusing on the polymorphisms obtained, highest levels of similarity were found for those genotypes sharing the same geographical origin (Yemen, Morocco). Furthermore, and perhaps more important, the results obtained suggest that there was no introgression by lemon or other citrus genomes into any of the citrons examined. Citron was found to have a unique cpDNA profile, similar only to $C$. indica (Nicolosi et al., 2000); in the present study all the citrons tested showed the specific citron cpDNA band.

From a botanical standpoint, the idea that the Morocco citron or, even the Yemen citron are endemic to those areas, appears naive indeed. Thus, the Morocco citron almost certainly originated many centuries ago in the Mediterranean.

The origin of the Yemen citron is not so clear at first sight. Its robust appearance is reminiscent of some Indian types of citrus (Hodgson et al., 1963), which were not investigated in detail, and the possibility of its arrival from India via the sea route deserves some consideration. However, the findings of the present study provide conclusive evidence that the Yemen 
citron is phylogenetically very close to the Mediterranean types, testifying to its probable Near East or Mediterranean origin.

Thus, all the types of citron we studied, including the Morocco and Yemen types have by all probability originated at some distant time in the Mediterranean basin.

But, how could the citrons from the Mediterranean get to be established in such distant areas as Morocco and Yemen?

The answer might be that citrons were grown, since ancient times, to a large extent, by the Jews and for the Jews, who were anxious to have them for their Tabernacles ritual. Both southern Morocco and Yemen were already inhabited by Jews, according to traditions of these communities, during the Roman era, about 2000 years ago. Citron fruit are rather hardy and the seeds maintained within them will remain viable for long periods of time. Presumably, in the course of their wandering, Jews brought citron fruit or seed with them and, wherever possible, established the culture of this unique citrus species. Thus, from a historical perspective, the results of the present study may be taken as evidence for the special role played by Jews in the spread of citrus.

\section{Literature Cited}

Bar-Joseph, M. 2003. Natural history of viroids-horticultural aspects, p. 246-251. In: A. Hadidi, R. Flores, J.W. Randles, and J.S. Semancik (eds.). Viroids. CSIRO Publ., Collingwood, Victoria, Australia.

Barrett, H.C. and A.M. Rhodes. 1976. A numerical taxonomic study of affinity relationships in cultivated Citrus and its close relatives. Syst. Bot. 1:105-136.
Calabrese, F. 1998. La favolosa storia degli agrumiThe fascinating history of citrus fruit. L'EPOS, Palermo, Italy.

Chapot, H. 1950. Un curieux cedrat Marocain (C.medica L.). Rev. Intl. Bot. Appl. Agr. Trop. 30:506-514.

Chapot, H. 1975. The citrus plant, p. 6-13. In: Citrus. CIBA-GEIGY Agrochemicals Tech. Monogr. 4. CIBA-GEIGY Ltd., Basle, Switzerland.

Demesure, B., N. Sodzi, and R.J. Petit. 1995. A set of universal primers for amplification of polymorphic non-coding regions of mitochondrial and chloroplast DNA in plants. Mol. Ecol. 4:129-131.

Deng, Z.N., A. Gentile, E. Nicolosi, F. Domina, A. Vardi, and E. Tribulato. 1995. Identification of in vivo and in vitro lemon mutants by RAPD markers. J. Hort. Sci .70:117-125.

Doyle, J.J. and J.L. Doyle. 1987. A rapid DNA isolation procedure for small quantities of fresh leaf tissue. Phytochem. Bul. 19:11-15.

Ferrari, G.B. 1646. Hesperides: sive De Malorum aureorum cultura et usu libri quatuor. Hermanni Scheus, Rome.

Gallesio, G. 1811. Traite du Citrus, p. 381. Louis Fantin, Paris.

Goldschmidt, E.E. 1976. Factors determining the shape of citrons. Israel J. Bot. 25:34-40.

Goldschmidt, E.E. 1981. The problem of the ' grafted citron' and the nature of our citron cultivars: Halachic and scientific considerations. Techumin 2:134-146 (Hebrew).

Greene, E.L. 1983. Landmarks of botanical history. Part II. Frank N. Egerton (ed.). Stanford Univ. Press, Stanford, Califo.

Hodgson, R.W. 1967. Horticultural varieties of citrus, p. 431-591. In: W. Reuther, H.J. Webber, and L.D. Batchelor (eds.). The citrus industry. vol. 1. Div.Agr. Sci., Univ. Calif., Berkeley.

Hodgson, R.W., R. Singh, and D. Singh. 1963. Some little known India citrus species. Calif. Citrog. 48:357-363.

Kim, M., W. Canio, S. Kessler, and N. Sinha. 2001.
Developmental changes due to long-distance movement of a homeobox fusion transcript in tomato. Science 293:287-289.

Moore, G.A. 2001. Oranges and lemons: Clues to the taxonomy of Citrus from molecular markers. Trends in Genetics, 17: 536-540.

Nei, M. and W.H. Li. 1979. Mathematical model for studying genetic variation in terms of restriction endonucleases. Proc. Natl. Acad. Sci. USA 76:3269-3273.

Nicolosi, E., Z.N. Deng, A. Gentile, S. La Malfa, G. Continella, and E. Tribulato. 2000. Citrus phylogeny and genetic origin of important species as investigated by molecular markers. Theor. Appl. Genet. 100(8):1155-1166.

Nicolosi, E., S. La Malfa, and E.E. Goldschmidt. 2000. Molecular analysis of the phylogenetic relationships among 12 citron accessions. Proc. Intl. Soc. Citricult. p.183.

Palauqui, J.C., T. Elmayan, J.M. Pollien, and H. Vaucheret. 1997. Systemic acquired silencing: transgene-specific post-transcriptional silencing is transmitted by grafting from silenced stocks to non-silenced scions. The EMBO J. 16:4738-4745.

Pease, A.S. 1933. Notes on ancient grafting. Trans. Amer.Philological Association 69:66-76.

Sonoda, S. and M. Nishiguchi. 2000. Graft transmission of post-transcriptional gene silencing: Target specificity for RNA degradation is transmissible between silenced and non-silenced plants, but not between silenced plants. Plant J. 21:1-8.

Swofford, D.L. 1993. PAUP: Phylogenetic analysis using parsimony. version 3.1. Ill. Nat. History Surv., Champaign, Ill.

Volkamer, J.C. 1708. Nürnbergische Hesperides, oder Grüendliche Beschreibung der edlen Citronat Citronen und Pomeranzen-Früchte. Nürnberg. vol. 2.

Tolkowsky, S. 1938. Hesperides. A history of the culture and use of citrus fruits, p. 371. John Bale, Sons and Curnow, London. 